\title{
Abiraterone/Prednisone/Triptorelin Regimen
}

National Cancer Institute

\section{Source}

National Cancer Institute. Abiraterone/Prednisone/Triptorelin Regimen. NCI Thesaurus.

Code C160540.

A regimen consisting of triptorelin, abiraterone, and prednisone that may be used in the treatment of certain types of prostate carcinoma. 